\title{
PTEN regulates colorectal epithelial apoptosis through Cdc42 signalling
}

\author{
R Deevi ${ }^{1,2}$, A Fatehullah ${ }^{1,2}$, I Jagan', M Nagaraju', V Bingham' and FC Campbell*, \\ 'Centre for Cancer Research and Cell Biology, Queen's University of Belfast, Lisbum Road, Belfast BT97BL, UK
}

\begin{abstract}
BACKGROUND: Phosphatase and tensin homologue deleted on chromosome I0 (PTEN) regulation of the Rho-like GTPase Cdc42 has a central role in epithelial polarised growth, but effects of this molecular network on apoptosis remain unclear.

METHODS: To investigate the role of Cdc42 in PTEN-dependent cell death, we used flow cytometry, in vitro pull-down assays, poly(ADP ribose) polymerase (PARP) cleavage and other immunoblots in isogenic PTEN-expressing and -deficient colorectal cells (HCTII6PTEN ${ }^{+1+}$, HCTII 6 PTEN $^{-1-}$, Caco2 and Caco2 ShPTEN cells) after transfection or treatment strategies.

RESULTS: The PTEN knockout or suppression by short hairpin RNA or small interfering RNA (siRNA) inhibited Cdc42 activity, PARP cleavage and/or apoptosis in flow cytometry assays. Transfection of cells with wild-type or constitutively active Cdc42 enhanced PARP cleavage, whereas siRNA silencing of Cdc42 inhibited PARP cleavage and/or apoptosis. Pharmacological upregulation of PTEN by sodium butyrate $(\mathrm{NaBt})$ treatment enhanced $\mathrm{Cdc} 42$ activity, PARP cleavage and apoptosis, whereas Cdc42 siRNA suppressed $\mathrm{NaBt}$-induced PARP cleavage. Cdc42-dependent signals can suppress glycogen synthase kinase- $\beta$ (GSK3 $\beta$ ) activity. Pharmacological inhibition of GSK3 $\beta$ by lithium chloride treatment mimicked effects of Cdc42 in promotion of PARP cleavage and/or apoptosis. CONCLUSION: Phosphatase and tensin homologue deleted on chromosome 10 may influence apoptosis in colorectal epithelium through Cdc42 signalling, thus providing a regulatory framework for both polarised growth and programmed cell death.

British Journal of Cancer (201 I) 105, 1313-1321. doi:I0.1038/bjc.201 I.384 www.bjcancer.com

Published online 27 September 2011

(c) 20I I Cancer Research UK
\end{abstract}

Keywords: apoptosis; PTEN; Cdc42; PARP; GSK3 $\beta$

Phosphatase and tensin homologue deleted on chromosome 10 (PTEN) dephosphorylates intracellular phosphatidylinositol 3,4,5 trisphosphate (Maehama and Dixon, 1999) and thus antagonises the phosphatidylinositol 3-kinase/AKT pathway (Sun et al, 1999). The PTEN loss in cancer states invokes unopposed AKT activity and phosphorylation of various substrates that enhance cell survival, including pro-caspase 9 (Cardone et al, 1998), BAD (Datta et al, 1997) and the forkhead factor, FKHR (Biggs et al, 1999). Although therapeutic targeting of AKT could provide proapoptotic cancer therapy (Bailey et al, 2006; Chee et al, 2007; Yap et al, 2008), effects of small interfering RNA (siRNA) knockdown of AKT on apoptosis are inconsistent (Koseoglu et al, 2007) and results from recent phase I and II clinical trials of AKT inhibitor monotherapy have been disappointing (Argiris et al, 2006; Yap et al, 2008; Gills and Dennis, 2009). Biological consequences of PTEN loss and AKT activation do not overlap completely (Lee et al, 2010), and deeper understanding of PTEN-regulated cell death may help delineate novel therapeutic strategies.

In physiological conditions, PTEN maintains tissue homeostasis by coordinated regulation of polarised cell growth (Kolsch et al, 2008) and morphogenesis (Martin-Belmonte et al, 2007), as well as cell death (Weng et al, 2001). The Rho-like GTP-binding protein Cdc42 (Cell division cycle 42) is a key mediator of PTEN-dependent

\footnotetext{
*Correspondence: Dr FC Campbell; E-mail: f.c.campbell@qub.ac.uk

2 These authors contributed equally to this work.

Received 3 June 2011; revised 25 August 2011; accepted 31 August 201 I; published online 27 September 201 I
}

cell polarisation (Higuchi et al, 2001) and morphogenesis (Martin-Belmonte et al, 2007). Cdc42 cycles between active GTPbound and inactive GDP-bound states and interacts with highly conserved polarity proteins partitioning defective homologue 6 (Par6) and atypical protein kinase C (aPKC). The resulting Cdc42/ Par6/aPKC complex deactivates glycogen synthase kinase-3 $\beta$ $($ GSK3 $\beta)$ by promotion of serine 9 (Ser9) phosphorylation (Etienne-Manneville and Hall, 2003). The GSK3 $\beta$ modulates microtubule dynamics implicated in cell polarisation processes (Zhou and Snider, 2005).

In addition to its effects on cell polarisation (Johnson, 1999; Etienne-Manneville, 2004), Cdc42-dependent signalling also influences growth (Cerione, 2004) and apoptosis (Chuang et al, 1997; $\mathrm{Na}$ et al, 1999; Melendez et al, 2011). As a target of the Cdc42/Par6/ aPKC complex (Etienne-Manneville and Hall, 2003), GSK3 $\beta$ integrates multiple signalling cascades (Doble and Woodgett, 2003) and has context-specific effects on apoptosis (Pap and Cooper, 1998; Hoeflich et al, 2000; Beurel and Jope, 2006). Glycogen synthase kinase- $3 \beta$ enhances survival of gastrointestinal cancer cells (Mai et al, 2009), and GSK3 $\beta$ knockout mice succumb to massive hepatic apoptosis (Hoeflich et al, 2000), indicating an important anti-apoptotic role.

Although PTEN influences tissue homeostasis through Cdc42 signalling (Langlois et al, 2010), the role of Cdc42 activity in PTENdependent cell death remains unclear. To investigate the role of PTEN in Cdc42-mediated apoptosis, we used paired isogenic human colorectal cancer (CRC) cell lines differing in PTEN status. We used parental HCT116PTEN ${ }^{+1+}$ cells and a knockout clone generated by a high-efficiency promoterless PTEN targeting vector 
(Lee et al, 2004). To address the phenotypic and genotypic heterogeneity of human CRC, we generated a second unrelated isogenic human colorectal model with genotype and phenotype differences from the HCT116 system. We used a Caco-2 parental cell line that expresses PTEN (Wang et al, 2007). Unlike HCT116 cells, Caco-2 cells are K-Ras wild type (wt), but APC mutant (Ilyas et al, 1997; Lawson et al, 2000; Hao et al, 2007; Database, 2011), and undergo apico-basolateral polarisation (Gilbert et al, 1991).

Here, we show that PTEN knockout in HCT116 colorectal cells or suppression by stable short hairpin RNA (shRNA) transfection in Caco 2 colorectal cells inhibits Cdc42 activity, poly(ADP ribose) polymerase (PARP) cleavage and/or apoptosis in flow cytometry assays of propidium iodide-labelled cells (PI-labelled apoptosis). Sodium butyrate $(\mathrm{NaBt})$ is a short-chain fatty acid that upregulates PTEN expression (Wang et al, 2001; Bai et al, 2010). In this study, $\mathrm{NaBt}$ treatment enhanced PTEN expression, Cdc42 activity and apoptosis, whereas siRNA knockdown of Cdc42 impeded NaBtinduced cell death. Lithium chloride ( $\mathrm{LiCl})$ treatment suppresses GSK3 $\beta$ (De Sarno et al, 2002). In the present study, LiCl treatment mimicked effects of Cdc42 in promotion of GSK3 $\beta$ Ser9 phosphorylation, PARP cleavage and apoptosis. Taken together, these data implicate $\mathrm{Cdc} 42$ signalling in PTEN regulation of apoptosis, in genotypically and phenotypically distinct colorectal epithelial lines.

\section{MATERIALS AND METHODS}

\section{Reagents and antibodies}

Laboratory chemicals were purchased from Sigma-Aldrich (Poole, UK), unless otherwise stated. GeneJuice transfection reagent was purchased from Novagen (Gibbstown, NJ, USA). Rabbit monoclonal anti-PTEN, anti-GSK3 $\beta$ and -p-GSK3 $\beta$ (Ser9) primary antibodies were purchased from Cell Signaling Technology (New England Biolabs Ltd, Hitchin, Herts, UK). Mouse monoclonal (MMC) anti-Cdc42 was obtained from BD Transduction Laboratories (San Diego, CA, USA), and MMC anti-GAPDH was obtained from Abcam (Cambridge, MA, USA). Depending on protein expression levels, LICOR (Infra-Red imaging system; LICOR Biosciences, Cambridge, UK) or enhanced chemiluminescence (Amersham, GE Healthcare, Buckinghamshire, UK) detection systems were used. Primary antibodies were therefore used with anti-rabbit LICOR IRDye 680, anti-mouse LICOR IRDye800 or horseradish peroxidase-conjugated anti-rabbit or anti-mouse secondary antibodies for western blotting. pcDNA3-Cdc42-wt (no. 12599), Cdc42 Q61L (constitutively active (CA); no. 12600), Cdc42 T17N (dominant negative (DN); no.12601), pcDNA-EGFP empty vector (EV), pMKO.1 puro PTEN shRNA (no. 10669) and pMKO.1 puro EV (no. 8452) were purchased from Addgene Inc., Cambridge, MA, USA. Lithium chloride and NaBt were dissolved in distilled water immediately before use.

\section{Cell culture and treatments}

$\mathrm{HCT}_{116 \mathrm{PTEN}^{-1-}}$ and HCT116PTEN ${ }^{+/+}$cells were cultured in McCoy's 5A media (Sigma-Aldrich, Dorset, UK) supplemented with $10 \%$ fetal calf serum (FCS), $1 \mathrm{~mm}$ L-glutamine, $1 \mathrm{~mm}$ sodium pyruvate and supplemented with antibiotics. Caco2 ShPTEN and Caco2 cells were cultured in Eagle's minimal essential medium supplemented with $10 \%$ FCS, $1 \mathrm{~mm}$ non-essential amino acids, $1 \mathrm{mM}$ L-glutamine and antibiotics at $37^{\circ} \mathrm{C}$ in $5 \% \mathrm{CO}_{2}$. Parental cells and clones have been passaged no more than 20 times, in accord with UKCCCR Guidelines (UKCCCR, 2000).

Cells were grown for 2-3 days until $60-70 \%$ confluence and then treated with the GSK3 $\beta$ inhibitor LiCl $1 \mathrm{~mm}$ (De Sarno et al, 2002) or NaBt $1 \mathrm{~mm}$ (Wang et al, 2001) for $24 \mathrm{~h}$. Drug-treated or -untreated cells were then lysed with ice-cold lysis buffer for
$15 \mathrm{~min}$. Cell lysate was collected, vortexed for $1 \mathrm{~min}$ and then centrifuged at $12400 \mathrm{~g}$ for $10 \mathrm{~min}$ at $4{ }^{\circ} \mathrm{C}$. Protein concentration was measured by the bicinchoninic acid kit using bovine serum albumin standards (Thermo Scientific, Barrington, IL, USA).

\section{Cell transfection}

HCT116PTEN $^{-/-}$, HCT116PTEN $^{+/+}$, Caco2 ShPTEN and Caco 2 cells were plated at $1.5 . \times 10^{5}$ cells per well in six-well plates and incubated for $24 \mathrm{~h}$ at $37^{\circ} \mathrm{C}$, and then transfected with $600 \mathrm{ng}$ DNA per well for all constructs. We used GeneJuice transfection reagent/ serum-free medium/DNA mix, according to manufacturer's instructions. Cells were incubated with DNA-GeneJuice complexes for $24 \mathrm{~h}$. Transfection medium was then replaced with normal culture medium. Cells were collected $48 \mathrm{~h}$ after transfection for PI staining and flow cytometry or lysed and probed as described in Protein extraction and western blotting.

\section{Stable retroviral transfections}

Caco2 cells were transfected using replication-defective retroviral vectors encoding PTEN shRNA or EV only in a puromycin selection cassette, as previously described (Boehm et al, 2005). Retroviral vectors were generated using the Phoenix retroviral expression system (Orbigen, San Diego, CA, USA; Geng et al, 2010). Briefly, Phoenix Eco retroviral packaging cells (Orbigen), purchased within the last 2 years, were transfected with pMKO.1 puro PTEN shRNA or pMKO.1 puro EV retroviral expression vectors (Addgene Inc.), and supernatant containing recombinant retroviral vectors encoding PTEN shRNA or EV only was collected after $48 \mathrm{~h}$. Viral supernatant was centrifuged at $2000 \mathrm{~g}$ at room temperature for $15 \mathrm{~min}$ to remove cell debris and then used immediately. Viral supernatant was added to $\mathrm{Caco} 2$ cultures for $48 \mathrm{~h}$ at $37^{\circ} \mathrm{C}$ in $5 \% \mathrm{CO}_{2}$. Caco2 transfectants were then incubated in $1 \mu \mathrm{g} \mathrm{ml}^{-1}$ puromycin for 7 days for selection of ShPTENor EV-only-positive subclones. HCT116 $\mathrm{PTEN}^{-1-}$ cells and HCT116PTEN $^{+1+}$ cells were a gift from Dr Tod Waldman, Georgetown University, USA. The HCT116PTEN ${ }^{-1-}$ knockout clone was generated from parental cells using a high-efficiency promoterless PTEN targeting vector, as previously described (Lee et al, 2004).

\section{Small interfering RNA-mediated knockdown of PTEN}

RNA interference-mediated knockdown of PTEN was performed by transfection of synthetic duplex RNA oligonucleotides, using Oligofectamine (Invitrogen, Carlsbad, CA, USA) according to manufacturers' instructions. On-Target plus SMART pool PTEN (catalog no. L-003023-00, Dharmacon, Fisher Scientific, Dublin, UK) and Cdc42 (catalog no. L-005057 from Dharmacon) siRNA oligonucleotides were used. On-Target plus non-targeting siRNAs were used as controls (catalog no. D-001810-01-05, Dharmacon). Briefly, Oligofectamine and Opti-Mem serum-free medium (Invitrogen) were mixed in $1: 3$ ratio, incubated at room temperature for $5 \mathrm{~min}$ and then added to siRNA, which was prediluted in Opti-Mem to final concentration of $50 \mathrm{nM}$ and then added to cultures. Cells were grown in $90 \mathrm{~mm}$ dishes and were transfected at $50-60 \%$ confluence by incubation in the above mixture. The medium was changed after $6 \mathrm{~h}$ and cells were harvested after $48 \mathrm{~h}$. The PTEN or Cdc42 expression was assayed by western blot as outlined in Protein extraction and western blotting.

\section{GST - PAK pull-down assay for Cdc42 activity}

Cells were lysed in buffer comprising $50 \mathrm{~mm}$ Tris- $\mathrm{HCl}, \mathrm{pH} 7.5,1 \%$ Triton X-100, $100 \mathrm{~mm} \mathrm{NaCl}, 10 \mathrm{~mm} \mathrm{MgCl}_{2}, 5 \%$ glycerol, $1 \mathrm{~mm}$ $\mathrm{Na}_{3} \mathrm{VO}_{4}$ and protease inhibitor cocktail (Roche, West Sussex, UK). Lysate was centrifuged at $12500 \mathrm{~g}$ for $10 \mathrm{~min}$. p21-activated kinase 
(PAK) binds specifically to active Cdc42 and Rac (Chuang et al, 1997). The GTP-bound form of endogenous or GFP-tagged Cdc42 was assayed by adding GST-PAK fusion protein coupled with glutathione sepharose 4B beads (GE Healthcare, Svensk, Sweden) to $1 \mathrm{mg}$ of cell lysate and then incubated at $4{ }^{\circ} \mathrm{C}$ on a rotating wheel for $1 \mathrm{~h}$. Beads were centrifuged for $1 \mathrm{~min}$, washed three times and then resuspended in $40 \mu \mathrm{l}$ of $2 \times$ Laemmli buffer containing $3 \mu \mathrm{l}$ of $1 \mathrm{M}$ DTT. Cdc42 activity was then assayed by western blotting, as outlined below. Experiments were repeated in triplicate.

\section{Protein extraction and western blotting}

Protocols were the same as we have previously described for other proteins (El-Tanani et al, 2004). Briefly, proteins were resolved using gel electrophoresis, followed by blotting onto nitrocellulose membranes. Membranes were probed using antibodies as indicated in the text. Experiments were repeated in triplicate.

\section{Apoptosis assays}

Cell death was assessed by PARP cleavage assay, as we have previously described (Collett and Campbell, 2006), and by flow cytometry, using PI for nuclear staining, to enable assay of the hypodiploid sub-G0/G1 peak (PI-labelled apoptosis; Riccardi and Nicoletti, 2006).

\section{Densitometry and statistical analysis}

Densitometric analysis of western blots was carried out using Image (Image processing and analysis in JAVA; NIH public domain software). Data analysis was carried out by ANOVA using SPSS (v16) for Windows (IBM Corp., New York, NY, USA). Descriptive statistics were expressed as the mean \pm s.e.m. Graphs were drawn using GraphPad Prism 5 (La Jolla, CA, USA).

\section{RESULTS}

PTEN expression associates with enhanced Cdc42 activation, increased PARP cleavage and apoptosis

To investigate PTEN regulation of $\mathrm{Cdc} 42$ and apoptosis, we used a PTEN knockout isogenic subclone of HCT116 cells together with parental cells (HCT116PTEN ${ }^{-1-}$ and HCT116PTEN ${ }^{+1+}$ cells, respectively). We also raised an unrelated $\mathrm{PTEN}$-deficient subclone of Caco 2 cells by PTEN shRNA stable transfection (Caco2 ShPTEN cells). Cdc42 activation was assessed by GST-PAK pull-down assay, whereas cell death was assayed by PARP cleavage immunoblots, as well as PI labelling and flow cytometry. The PTEN knockout or suppression was associated with lower Cdc42 activation and PARP cleavage in HCT116PTEN ${ }^{-1-}$ and Caco2 ShPTEN cells than in parental HCT116PTEN ${ }^{+/+}$and Caco 2 cells, respectively (Figures $1 \mathrm{a}$ and $\mathrm{b}$ ). Flow cytometry assays were conducted in HCT116 clones only. Analysis of PI-stained cells after gating of debris or necrotic cells showed apoptosis in $9.25 \pm 0.98 \%$ vs $16.75 \pm 1.5 \%$ in $\mathrm{HCT}_{116 \mathrm{PTEN}^{-l-}}$ vs $\mathrm{HCT}^{-16 \mathrm{PTEN}^{+}++}$cells (Figures $1 \mathrm{c}$ and $\mathrm{d}$ ). Transfection of HCT116PTEN ${ }^{+/+}$or Caco2 cells with PTEN siRNA suppressed PARP cleavage (Figure 1e).

\section{Cdc42 is implicated in PTEN-dependent cell death}

To investigate the role of Cdc42 in PTEN-dependent cell death, we transfected cells with wt, CA or DN Cdc42 constructs. Transfection of wt and CA Cdc42 increased the levels of active Cdc42 and PARP cleavage in all cell types (Figure 2a). Although effects of DN Cdc42 appeared inconsistent (Figure 2a), silencing of Cdc42 by siRNA transfection inhibited PARP cleavage (Figure 2b) and PI-labelled apoptosis in HCT116PTEN ${ }^{+/+}$cells (Figures $2 \mathrm{c}$ and d). Taken together, these data implicate Cdc42 in PTEN-dependent cell death in colorectal epithelium.

\section{NaBt treatment induces PTEN-dependent Cdc42 activation, PARP cleavage and PI-labelled apoptosis}

Sodium butyrate is a short-chain fatty acid that upregulates PTEN (Wang et al, 2007) and induces apoptosis in colorectal epithelium (Hague and Paraskeva, 1995). The NaBt treatment enhanced PTEN expression, Cdc42 activation and PARP cleavage in HCT116PTEN $^{+1+}$ and Caco 2 cells and significantly enhanced PI-labelled apoptosis in HCT116PTEN ${ }^{+1+}$ cells. Conversely, PTEN knockout or deficiency attenuated NaBt treatment effects on Cdc42 activity, PARP cleavage and/or PI-labelled apoptosis (Figures $3 a-c)$. Independent and interactive effects of PTEN expression and $\mathrm{NaBt}$ treatment on PI-labelled apoptosis were significant $(P<0.001$; two-way ANOVA). To investigate the role of Cdc42 in NaBt-induced cell PARP cleavage, we conducted Cdc42 siRNA knockdown experiments. Cdc42 siRNA inhibited Cdc42 expression and PARP cleavage in vehicle-only- and NaBt-treated HCT116PTEN $^{-l-}$ and HCT116PTEN ${ }^{+l+}$ cells (Figure $3 \mathrm{~d}$ ).

\section{Pharmacological suppression of GSK3 $\beta$ signalling}

As Cdc42-dependent signals may suppress GSK3 $\beta$ (EtienneManneville and Hall, 2003), a context-specific regulator of apoptosis (Beurel and Jope, 2006), we used pharmacological inhibitor studies to explore the role of GSK3 $\beta$ in apoptosis of PTEN-expressing or -deficient colorectal cells. Treatment of cells with the GSK $3 \beta$ inhibitor, $\mathrm{LiCl}$, promoted GSK3 $\beta$ Ser9 phosphorylation and enhanced PARP cleavage. These effects were reduced by PTEN knockout or deficiency in HCT116PTEN ${ }^{-1-}$ or Caco 2 ShPTEN cells, respectively (Figure 4a). Similarly in flow cytometry assays, LiCl enhanced PI-labelled apoptosis in HCT116PTEN ${ }^{+1+}$ cells but effects were diminished by PTEN knockout in HCT116PTEN $^{-1-}$ cells (Figures $4 \mathrm{~b}$ and c). Lithium chloride treatment also enhanced PTEN expression and Cdc42 activity in PTEN-expressing cell lines (Figure 4a). Interactive effects of $\mathrm{LiCl}$ treatment and PTEN status on PI-labelled apoptosis were significant $(P<0.001$; two-way ANOVA), which may suggest involvement of GSK3 $\beta$ in PTEN/Cdc42-dependent cell death.

\section{DISCUSSION}

Phosphatase and tensin homologue deleted on chromosome 10 expression in murine fibroblasts can be associated with suppression of GTP-bound Cdc42 (Liliental et al, 2000). Conversely, PTEN promotes membrane recruitment and activation of Cdc42, whereas siRNA PTEN knockdown suppresses Cdc42 activity in MDCK epithelial cultures (Martin-Belmonte et al, 2007). Hence, PTEN may coordinate Cdc42 signalling through cell- or context-specific mechanisms. In the present study, we found higher Cdc42 activity in PTEN-expressing colorectal epithelial cells than in PTEN-null or -deficient clones. Furthermore, siRNA PTEN knockdown in parental cells inhibited Cdc42 activation. In accord with its proapoptotic role (Lu et al, 1999; Weng et al, 2001), we found that PTEN deletion or suppression in HCT116PTEN ${ }^{-1-}$ or Caco 2 ShPTEN cells or siRNA knockdown of PTEN in HCT116PTEN ${ }^{+1+}$ and $\mathrm{Caco} 2$ cells inhibited PARP cleavage. Furthermore, flow cytometry analysis of the sub-G0/G1 fraction of cells, after PI staining and appropriate gating of debris and/or necrotic cells showed, reduced apoptosis in HCT116PTEN ${ }^{-1-} v s$ HCT116PTEN $^{+/+}$cells.

We conducted transfection studies to investigate the role of Cdc42 signalling in PTEN-mediated apoptosis. Transfection of cells with wt or CA Cdc42 enhanced Cdc42 activity and PARP cleavage, but effects of DN Cdc42 appeared less consistent. As DN Cdc42 mutants may have non-target effects by sequestering GEFs 

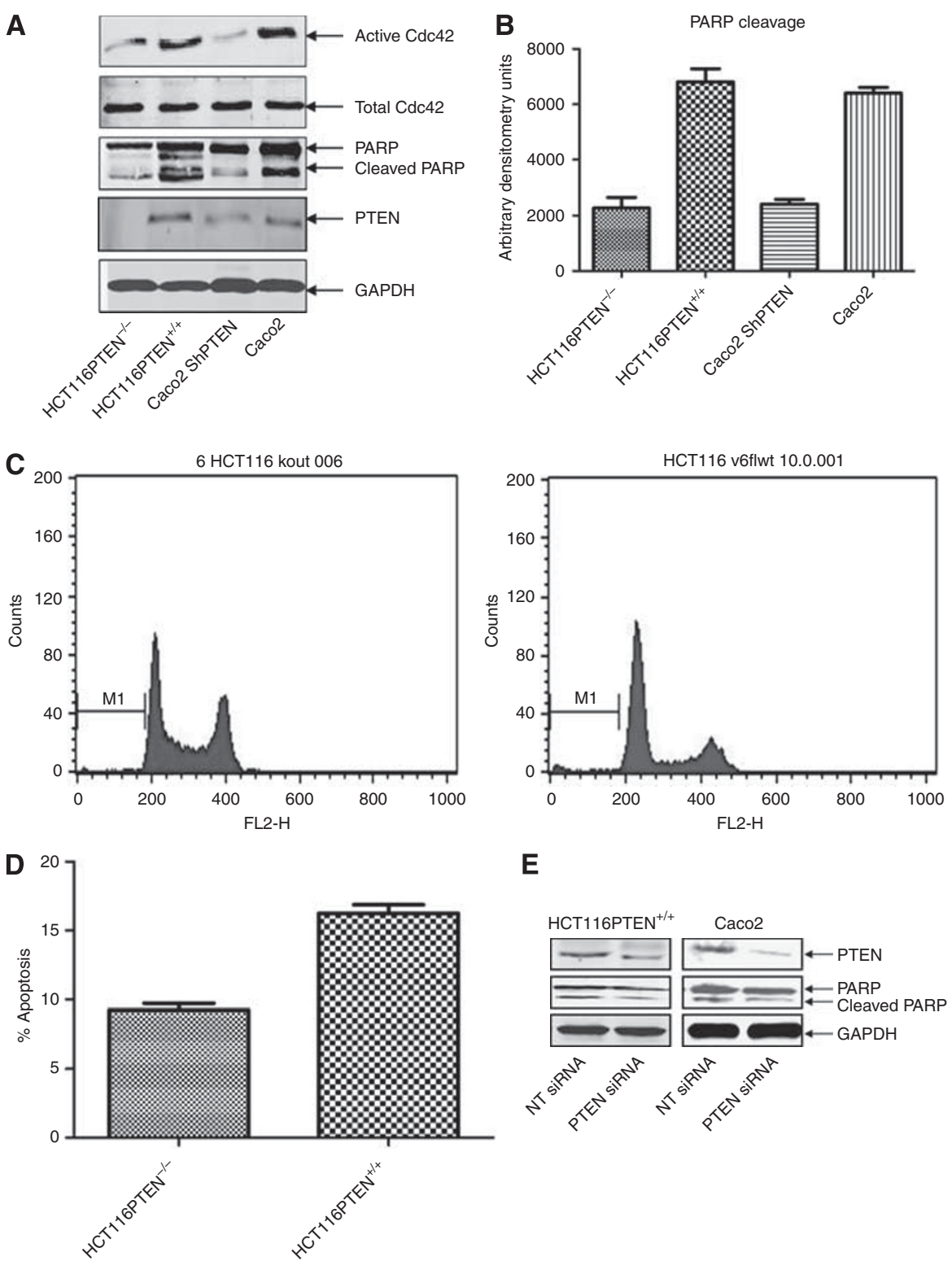

E

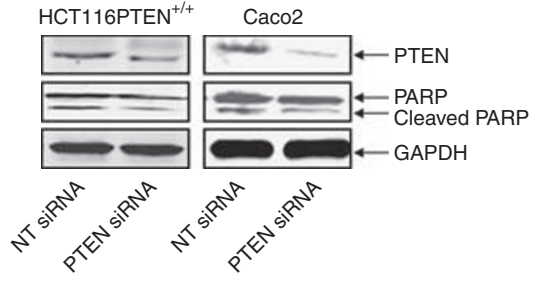

Figure I Phosphatase and tensin homologue deleted on chromosome 10 regulates apoptosis through activation of Cdc 42 in colorectal epithelial cells. (A) Cdc42 activity and PARP cleavage in PTEN-deficient or -expressing colorectal cells. HCT I I 6PTEN ${ }^{-9}$, HCT I I 6PTEN ${ }^{+/+}$, Caco2 ShPTEN and Caco2 colorectal epithelial cells were lysed, immunoblotted with anti-PTEN, anti-PARP, anti-Cdc42 and anti-GAPDH. Active Cdc42 was assessed by GST-PAK pull-down assay $(n=3)$. (B) Summary effects of PTEN expression on PARP cleavage. Densitometry assays showed lower PARP cleavage in PTEN-deficient HCTII6PTEN ${ }^{-1-}$ and Caco2 ShPTEN cells than in parental HCTI I 6PTEN ${ }^{+1+}$ or Caco2 cells, respectively $(P<0.00$ I; ANOVA; $n=3)$. $(\mathbf{C})$ Effects of PTEN expression on PI-labelled apoptosis in HCTI 16 clones. DNA histogram of the sub-G0/GI fraction of PI-stained cells (region MI) by flow cytometry after elimination of residual debris. By this method, apoptosis was quantified as $9.35 \pm 0.96 \%$ vs $16.75 \pm 1.5 \%$ in HCTII I PTEN $^{-1-}$ vs HCTII6PTEN HC $^{+1+}$ cells $(P<0.00$ I; ANOVA). (D) Summary effects of PTEN expression on PI-labelled apoptosis in HCTII 6 clones. Propidium iodide-labelled apoptosis (\% Apoptosis) was lower in HCTI I 6PTEN ${ }^{-1-}$ than in HCTI I 6PTEN ${ }^{+1+}$ cells $(n=3 ; P<0.001$; ANOVA). (E) Effects of PTEN siRNA knockdown on PARP cleavage. Small interfering RNA knockdown of PTEN in HCTII6PTEN ${ }^{+/+}$or Caco2 cells suppresses PARP cleavage.

for different Rho-family GTPases (Feig, 1999; Wang et al, 2003), we also silenced Cdc42 by siRNA knockdown. This step suppressed PARP cleavage and PI-labelled apoptosis in HCT116PTEN ${ }^{+1+}$ cells. In addition to siRNA methods, we also used pharmacological strategies. Sodium butyrate enhances PTEN-mediated apoptosis in colorectal epithelium (Wang et al, 2007). In the present study, we found that NaBt treatment substantively enhanced PTEN expression, Cdc42 activation, PARP cleavage and or PI-labelled apoptosis in HCT116PTEN ${ }^{+/+}$and/or Caco2 cells. Conversely, NaBt effects on PARP cleavage and PI-labelled apoptosis were attenuated by PTEN deletion or deficiency, in HCT116PTEN ${ }^{-1-}$ or Caco2
ShPTEN cells respectively. Furthermore, siRNA knockdown of Cdc42 suppressed NaBt induced PARP cleavage. Although $\mathrm{NaBt}$ may have off-target effects involving histone deacetylase inhibition (Walker et al, 2001) or vitamin D receptor activation (Gaschott and Stein, 2003), these pathways are not known to have a key role in Cdc42 activation. Taken together, these data implicate both PTEN and Cdc42 in NaBt-induced apoptotic cell death.

Cdc42-regulated signal transduction activates polarity proteins Par6 and aPKC (Cau and Hall, 2005; Schlessinger et al, 2007), which may regulate cell death through GSK3 $\beta$ (Kim et al, 2007). Although it is CA in resting cells (Frame and Cohen, 2001; 


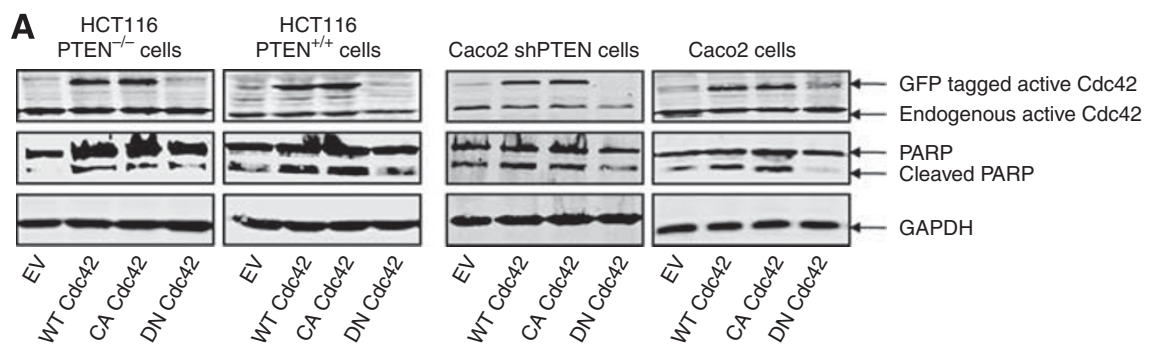

B

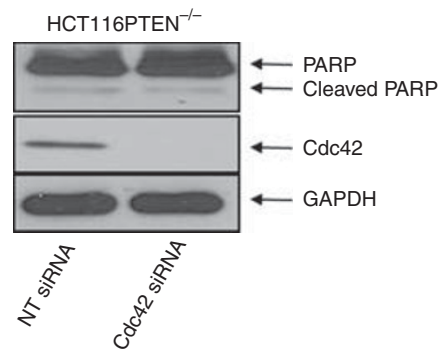

C

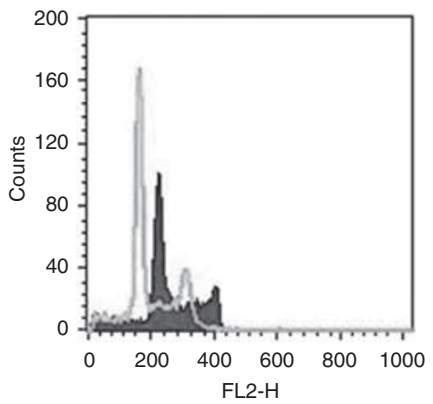

D

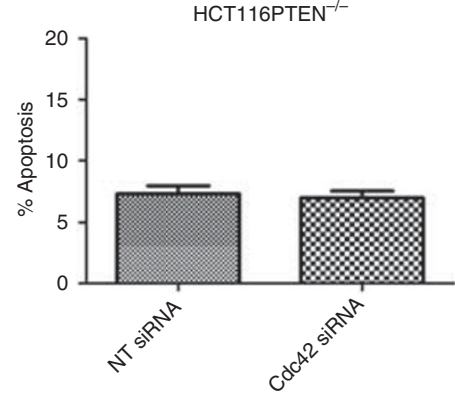

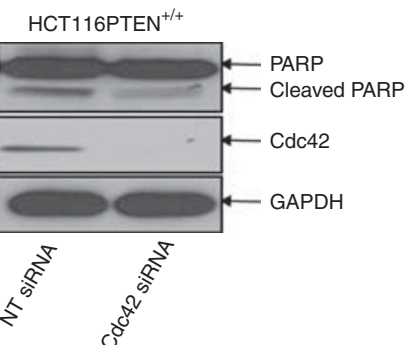
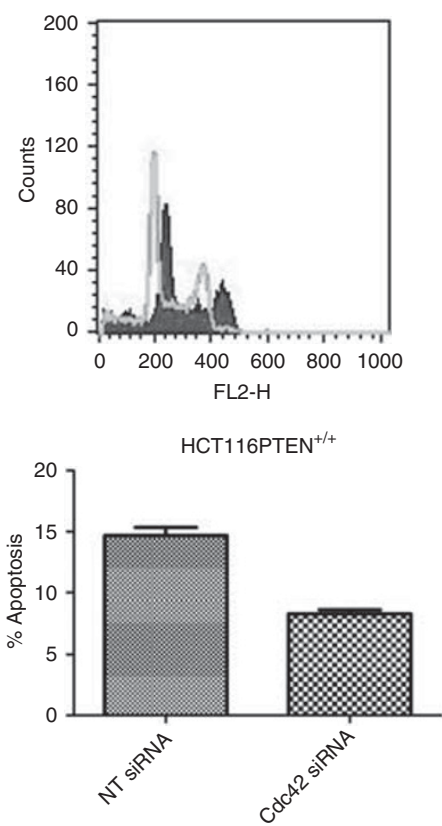

Figure 2 Cdc42 mediates PTEN-dependent apoptosis in epithelial cells. (A) Effects of Cdc42 transfection on PARP cleavage. HCTII6PTEN ${ }^{-1-}$, HCTII6PTEN ${ }^{+1+}$, Caco2 ShPTEN and Caco2 cells were transfected with GFP-tagged EV-only, wt, CA and DN Cdc42 in expression vectors. The GFPtagged transfected and endogenous Cdc42 activity and PARP cleavage are shown. The GFP-tagged Cdc42 activity and PARP cleavage are enhanced by wt and CA Cdc42 transfections. (B) Effects of Cdc42 siRNA knockdown on PARP cleavage. Transfection of HCTI $6 \mathrm{PTEN}^{-1-}$ and HCTI 6 PTEN $+1+$ cells with scrambled non-targeting (NT) siRNA or Cdc42-targeting siRNA (Cdc42 siRNA). Cdc42 siRNA suppressed PARP cleavage in HCTI I 6PTEN ${ }^{+/+}$cells. (C) Effects of Cdc42 siRNA knockdown on PI-labelled apoptosis. DNA histograms of the sub-G0/GI fraction of Pl-stained HCTI I6PTEN ${ }^{-1-}$ cells (left panel) and HCTI I 6PTEN ${ }^{+1+}$ cells (right panel) after transfection with NT siRNA (solid histogram) of Cdc42 siRNA (overlay). Transfection of Cdc42 siRNA depresses the sub-G0/GI apoptotic peak in HCTI I 6PTEN ${ }^{+1+}$ cells, in flow cytometry assays. (D) Summary effects of Cdc42 siRNA knockdown on PI-labelled apoptosis. Transfection with Cdc42-targeting siRNA (Cdc42 siRNA) inhibited PI-labelled apoptosis in HCTI I 6PTEN ${ }^{+/+}$cells $(n=3 ; P<0.00$ I; ANOVA).

Jope and Johnson, 2004), GSK3 $\beta$ may be inactivated by phosphorylation at Ser9 by AKT kinase activity (Cross et al, $1995)$ or by the Cdc42/Par6/aPKC polarisation complex (EtienneManneville and Hall, 2003). However, functional redundancy of AKT suppression of GSK $3 \beta$ has been shown in HCT116 cells by knockout studies (Ericson et al, 2010). Caco2 cells retain strong Cdc42 activity (Koch et al, 2009) that could influence their cellspecific GSK3 $\beta$ phosphorylation status (Etienne-Manneville and Hall, 2003). In the present study, we found that PTEN-expressing HCT116PTEN $^{+1+}$ and Caco2 cells had low-level AKT activity (data not shown) but higher Cdc42 activity and GSK3 $\beta$ Ser9 phosphorylation vs HCT116PTEN ${ }^{-1-}$ and Caco2 ShPTEN cells.

As GSK $3 \beta$ has context-specific effects on apoptosis (Beurel and Jope, 2006), we investigated its role in PTEN-dependent cell death in HCT116 or Caco2 clones by $\mathrm{LiCl}$ pharmacological inhibition (De Sarno et al, 2002). Although LiCl may have off-targets effects, its predominant known function in colorectal epithelium is a Wnt mimetic and suppressor of GSK3 $\beta$ (Dihlmann et al, 2003). In the present study, LiCl treatment enhanced GSK3 $\beta$ Ser9 phosphorylation, increased PARP cleavage and PI-labelled apoptosis, thus 


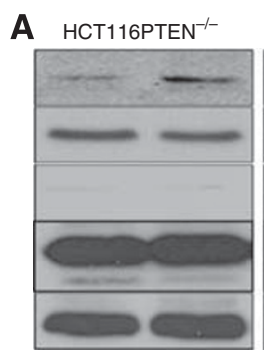

B

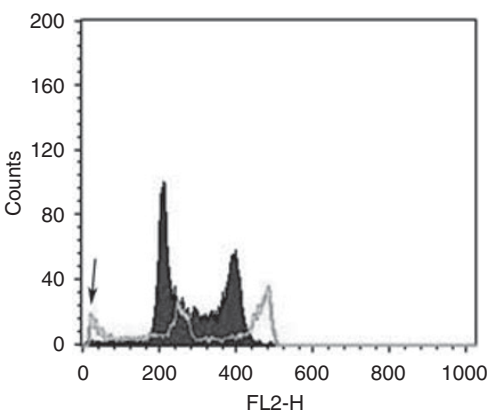

C

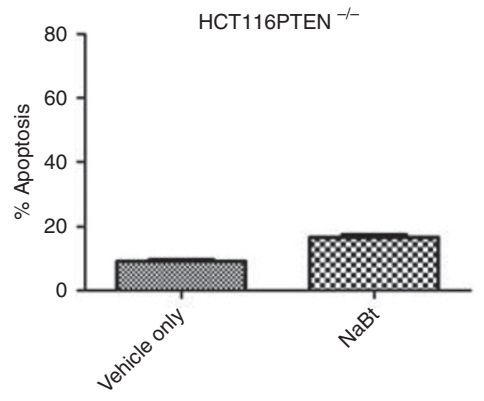

D
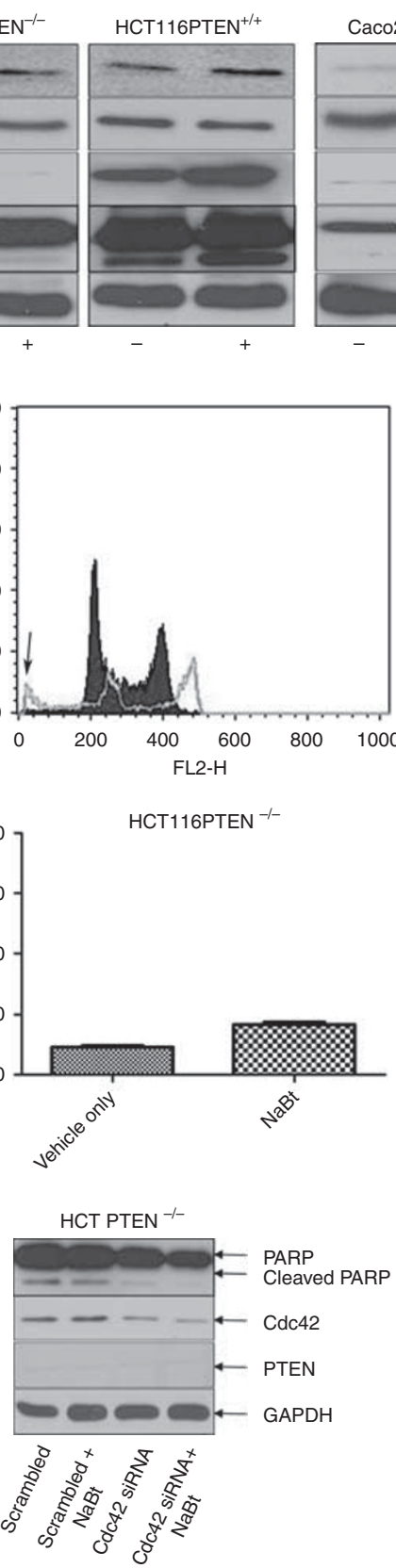
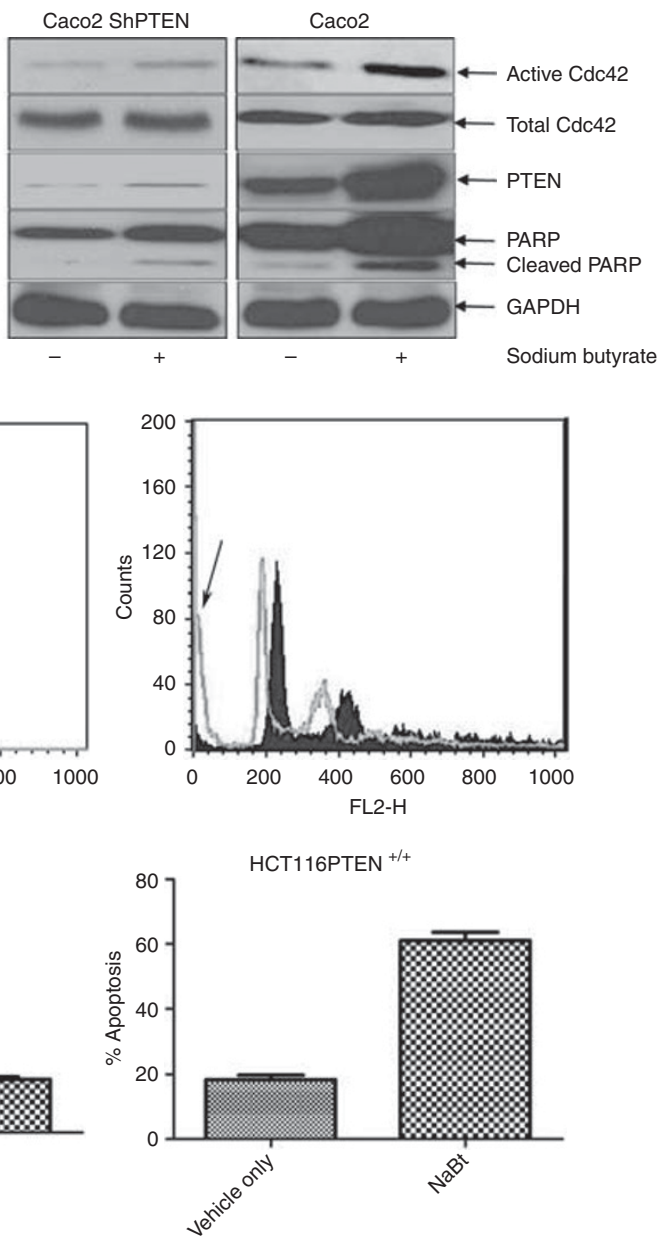

HCT PTEN ${ }^{+/+}$

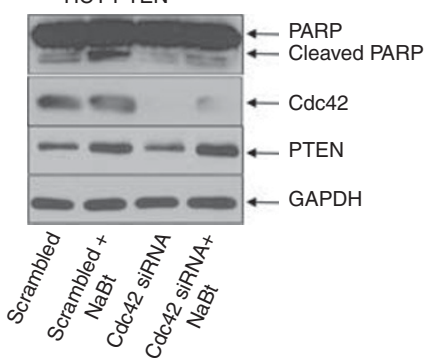

Figure 3 Effects of NaBt treatment. (A) Effects of NaBt treatment on PTEN, Cdc42 and PARP cleavage. HCTI I 6PTEN ${ }^{-1-}$, HCTI I 6PTEN $+/+$, Caco2 ShPTEN and $\mathrm{Caco} 2$ cells were treated by medium only or NaBt, then lysed and assayed for PTEN expression, Cdc 42 activity and PARP cleavage. Sodium butyrate treatment upregulated PTEN, enhanced Cdc42 activity and promoted PARP cleavage in HCTII6PTEN ${ }^{+/+}$and Caco2 cells. Sodium butyrate treatment effects on Cdc42 activity and PARP cleavage were blunted by PTEN knockout or deficiency in HCTII 6PTEN ${ }^{-1-}$ and Caco2 ShPTEN cells, respectively. (B) Effects of NaBt treatment on PI-labelled apoptosis. DNA histograms of the sub-G0/GI fraction of PI-labelled apoptotic cell death in $\mathrm{HCTI}$ I6PTEN ${ }^{-1-}$ cells (left panel) or HCTI I6PTEN ${ }^{+/+}$cells (right panel) after treatment by vehicle only (solid histogram) or NaBt (overlay). Arrows denote sub-GO/GI apoptosis peaks induced by $\mathrm{NaBt}$ treatment in HCTII6PTEN ${ }^{-1-}$ and HCTII6PTEN ${ }^{+1+}$ cells in flow cytometry assays. (C) Summary effects of NaBt treatment on PI-labelled apoptosis. Sodium butyrate treatment enhanced PI-labelled apoptosis in HCTI I6PTEN ${ }^{+/+}$cells $\left(P<0.00\right.$ I; ANOVA) but was less effective in HCTII6PTEN ${ }^{-1}$ cells. (D) Effects of Cdc42 SiRNA knockdown on NaBt-induced PARP cleavage. HCTII6PTEN ${ }^{-1-}$ and HCTII6PTEN ${ }^{+1+}$ cells were transfected with NT or Cdc42 siRNA and treated with vehicle only or NaBt. Cdc42, PARP and GAPDH were detected by probing with corresponding anti-primary antibodies, followed by appropriate horseradish peroxidase-conjugated secondary antibodies.

indicating an anti-apoptotic role for GSK3 $\beta$ in the colorectal epithelial model systems. Furthermore, effects of $\mathrm{LiCl}$ on GSK3 $\beta$ Ser9 phosphorylation, PARP cleavage and apoptosis were attenuated by PTEN knockout or suppression in HCT116PTEN ${ }^{-1-}$ and Caco2 ShPTEN cells, indicating synergy between PTEN expression and $\mathrm{LiCl}$ treatment. We also found that $\mathrm{LiCl}$ treatment enhanced
PTEN expression and Cdc42 activity in HCT116PTEN ${ }^{+/+}$and Caco 2 cells. These findings accord with previous studies that have shown that GSK3 $\beta$ destabilises PTEN by promotion of PTEN phosphorylation at Thr 366 (Al-Khouri et al, 2005) and that PTEN expression may be enhanced by GSK3 $\beta$ inhibitor treatment (Maccario et al, 2007). Phosphatase and tensin homologue deleted 
A
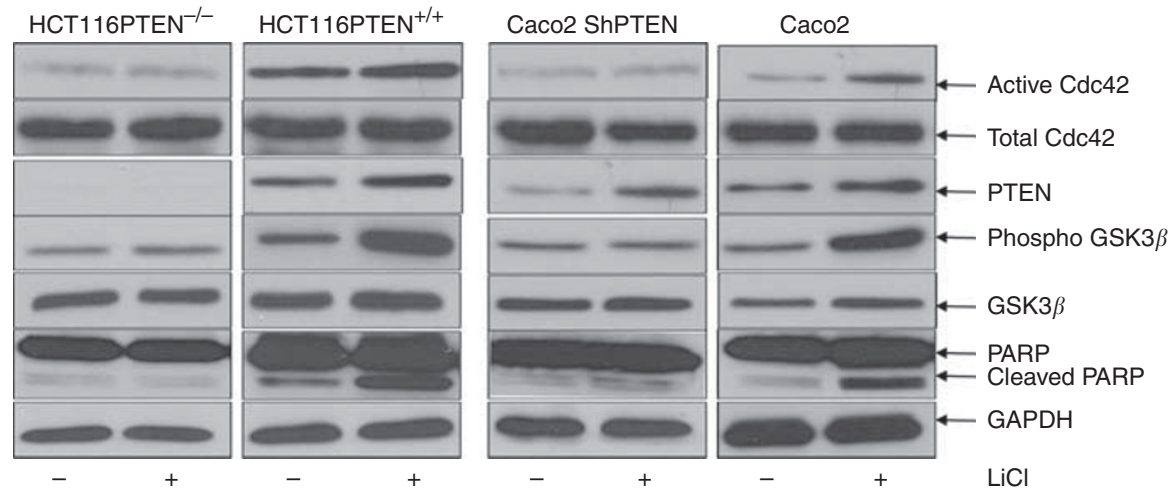

B
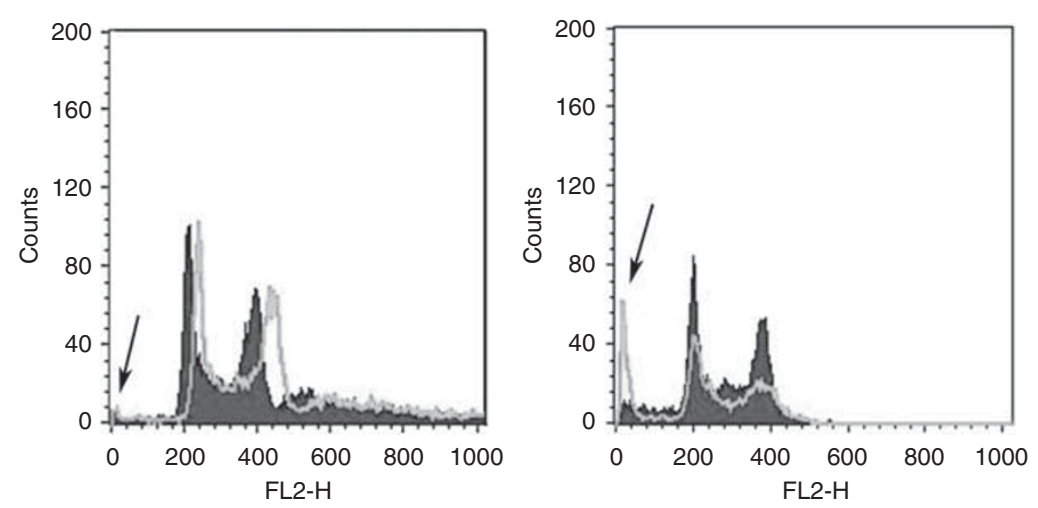

C
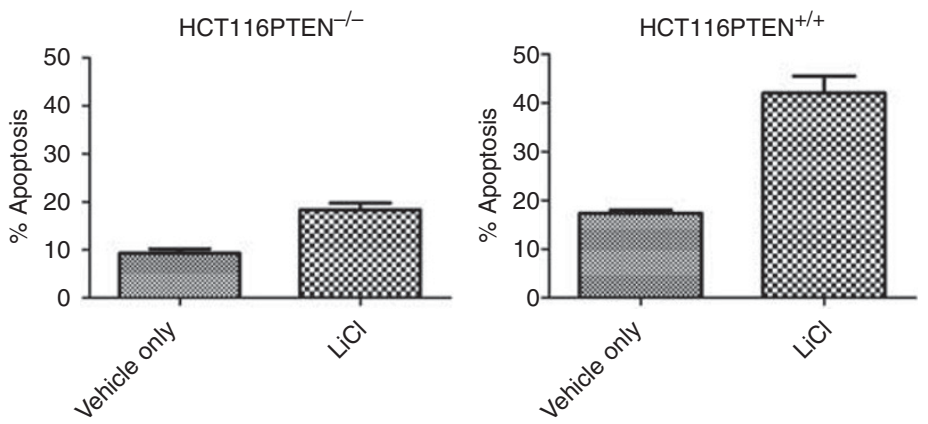

Figure 4 Effects of pharmacological suppression of GSK3 $\beta$. (A) Effects of LiCl treatment on PARP cleavage. HCTII6PTEN ${ }^{-1-}$, HCTII6PTEN $+1+$, $\mathrm{Caco} 2 \mathrm{ShPTEN}$ and $\mathrm{Caco} 2$ cells were treated with vehicle only $(-)$ or $\mathrm{LiCl}(\mathrm{I} \mathrm{mM} ;+)$. The LiCl treatment enhanced GSK3 $\beta$ Ser9 phosphorylation and PARP cleavage, to a greater extent in HCTII 6PTEN ${ }^{+1+}$ and Caco2 cells than in HCTII 6PTEN ${ }^{-1-}$ or Caco2 ShPTEN cells. The LiCl treatment also enhanced PTEN expression and Cdc42 activation in HCTII6PTEN ${ }^{+1+}$ and Caco2 cells. (B) Effects of LiCl treatment on PI-labelled apoptosis. DNA histograms of the sub-G0/G I fraction of PI-labelled apoptotic cell death in HCTI I 6PTEN ${ }^{-1-}$ cells (left panel) and HCTI I 6PTEN ${ }^{+/+}$cells (right panel) after

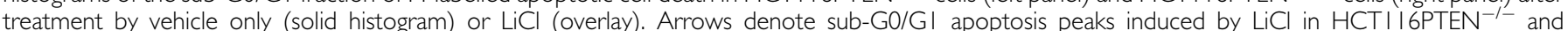

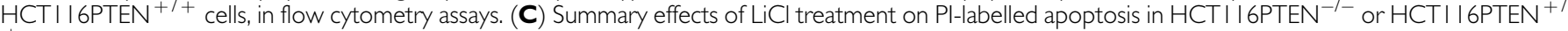
${ }^{+}$cells. Interactive effects of LiCl treatment and PTEN status on PI-labelled apoptosis (\% Apoptosis) were significant $(P<0.00 I ; n=3)$.

on chromosome 10 expression and $\mathrm{LiCl}$ treatment may thus share a common pathway of effect involving Cdc42 activation and GSK $3 \beta$ Ser9 phosphorylation in promotion of PARP cleavage and apoptosis.

Previous studies have shown regulatory coupling of cytoskeleton integrity and cell death by PTEN- (Vitolo et al, 2009; Tang et al, 2011) and Cdc42-dependent polarisation signalling (Warner et al, 2010). These processes may be implicated in eradication of cells that detach from supporting matrix or tissues (Cheng et al, 2004; Vitolo et al, 2009; Liu et al, 2011). In the present study, we show that PTEN-mediated PARP cleavage and apoptosis involves Cdc42 activity and may involve GSK3 $\beta$ Ser9 phosphorylation. Loss of these activities during cancer development may be implicated in unrestrained growth and formation of viable colonies from detached, depolarised neoplastic cells during tumour progression.

\section{ACKNOWLEDGEMENTS}

The authors gratefully acknowledge the support of the Wellcome Trust (WT081232MA) for financial support. We are greatly indebted to Dr T Waldman, Georgetown University for supply of PTEN $^{+/+}$and ${ }^{-/-}$HCT116 cells.

\section{Conflict of interest}

The authors declare no conflict of interest. 


\section{REFERENCES}

Al-Khouri AM, Ma Y, Togo SH, Williams S, Mustelin T (2005) Cooperative phosphorylation of the tumor suppressor phosphatase and tensin homologue (PTEN) by casein kinases and glycogen synthase kinase 3beta. J Biol Chem 280(42): 35195-35202

Argiris A, Cohen E, Karrison T, Esparaz B, Mauer A, Ansari R, Wong S, Lu Y, Pins M, Dancey J, Vokes E (2006) A phase II trial of perifosine, an oral alkylphospholipid, in recurrent or metastatic head and neck cancer. Cancer Biology Ther 5(7): 766-770

Bai Z, Zhang Z, Ye Y, Wang S (2010) Sodium butyrate induces differentiation of gastric cancer cells to intestinal cells via the PTEN/phosphoinositide 3-kinase pathway. Cell Biol Int 34(12): $1141-1145$

Bailey HH, Mahoney MR, Ettinger DS, Maples WJ, Fracasso PM, Traynor AM, Erlichman C, Okuno SH (2006) Phase II study of daily oral perifosine in patients with advanced soft tissue sarcoma. Cancer 107(10): $2462-2467$

Beurel E, Jope RS (2006) The paradoxical pro- and anti-apoptotic actions of GSK3 in the intrinsic and extrinsic apoptosis signalling pathways. Prog Neurobiol 79(4): $173-189$

Biggs 3rd WH, Meisenhelder J, Hunter T, Cavenee WK, Arden KC (1999) Protein kinase B/Akt-mediated phosphorylation promotes nuclear exclusion of the winged helix transcription factor FKHR1. Proc Natl Acad Sci USA 96(13): 7421-7426

Boehm JS, Hession MT, Bulmer SE, Hahn WC (2005) Transformation of human and murine fibroblasts without viral oncoproteins. Mol Cell Biol 25(15): $6464-6474$

Cardone MH, Roy N, Stennicke HR, Salvesen GS, Franke TF, Stanbridge E, Frisch S, Reed JC (1998) Regulation of cell death protease caspase-9 by phosphorylation. Science 282(5392): 1318-1321

Cau J, Hall A (2005) Cdc42 controls the polarity of the actin and microtubule cytoskeletons through two distinct signal transduction pathways. J Cell Sci 118(Pt 12): 2579-2587

Cerione RA (2004) Cdc42: new roads to travel. Trends Cell Biol 14(3): $127-132$

Chee KG, Longmate J, Quinn DI, Chatta G, Pinski J, Twardowski P, Pan CX, Cambio A, Evans CP, Gandara DR, Lara Jr PN (2007) The AKT inhibitor perifosine in biochemically recurrent prostate cancer: a phase II California/Pittsburgh cancer consortium trial. Clin Genitourin ancer 5(7): $433-437$

Cheng TL, Symons M, Jou TS (2004) Regulation of anoikis by Cdc42 and Rac1. Exp Cell Res 295(2): 497-511

Chuang TH, Hahn KM, Lee JD, Danley DE, Bokoch GM (1997) The small GTPase Cdc42 initiates an apoptotic signalling pathway in Jurkat T lymphocytes. Mol Biol Cell 8(9): 1687-1698

Collett GP, Campbell FC (2006) Overexpression of p65/RelA potentiates curcumin-induced apoptosis in HCT116 human colon cancer cells. Carcinogenesis 27(6): 1285-1291

Cross DA, Alessi DR, Cohen P, Andjelkovich M, Hemmings BA (1995) Inhibition of glycogen synthase kinase- 3 by insulin mediated by protein kinase B. Nature 378(6559): 785-789

Database - Wellcome Trust Sanger Cancer cell line project (2011) www.sanger.ac.uk/genetics/CGP/CellLines/

Datta SR, Dudek H, Tao X, Masters S, Fu H, Gotoh Y, Greenberg ME (1997) Akt phosphorylation of BAD couples survival signals to the cell-intrinsic death machinery. Cell 91(2): 231-241

De Sarno P, Li X, Jope RS (2002) Regulation of Akt and glycogen synthase kinase-3 beta phosphorylation by sodium valproate and lithium. Neuropharmacology 43(7): $1158-1164$

Dihlmann S, Klein S, Doeberitz Mv MK (2003) Reduction of beta-catenin/ T-cell transcription factor signaling by aspirin and indomethacin is caused by an increased stabilization of phosphorylated beta-catenin. $\mathrm{Mol}$ Cancer Ther 2(6): 509-516

Doble BW, Woodgett JR (2003) GSK-3: tricks of the trade for a multitasking kinase. J Cell Sci 116(Pt 7): 1175-1186

El-Tanani M, Platt-Higgins A, Rudland PS, Campbell FC (2004) Ets gene PEA3 cooperates with beta-catenin-Lef-1 and c-Jun in regulation of osteopontin transcription. J Biol Chem 279(20): 20794-20806

Ericson K, Gan C, Cheong I, Rago C, Samuels Y, Velculescu VE, Kinzler KW, Huso DL, Vogelstein B, Papadopoulos N (2010) Genetic inactivation of AKT1, AKT2, and PDPK1 in human colorectal cancer cells clarifies their roles in tumor growth regulation. Proc Natl Acad Sci USA 107(6): $2598-2603$
Etienne-Manneville S (2004) Cdc42 - the centre of polarity. J Cell Sci 117(Pt 8): $1291-1300$

Etienne-Manneville S, Hall A (2003) Cdc42 regulates GSK-3beta and adenomatous polyposis coli to control cell polarity. Nature 421(6924): $753-756$

Feig LA (1999) Tools of the trade: use of dominant-inhibitory mutants of Ras-family GTPases. Nat Cell Biol 1(2): E25-E27

Frame S, Cohen P (2001) GSK3 takes centre stage more than 20 years after its discovery. Biochem J 359(Pt 1): $1-16$

Gaschott T, Stein J (2003) Short-chain fatty acids and colon cancer cells: the vitamin D receptor-butyrate connection. Recent Results Cancer Res 164: 247-257

Geng D, Zheng L, Srivastava R, Velasco-Gonzalez C, Riker A, Markovic SN, Davila E (2010) Amplifying TLR-MyD88 signals within tumor-specific $\mathrm{T}$ cells enhances antitumor activity to suboptimal levels of weakly immunogenic tumor antigens. Cancer Res 70(19): $7442-7454$

Gilbert T, Le Bivic A, Quaroni A, Rodriguez-Boulan E (1991) Microtubular organization and its involvement in the biogenetic pathways of plasma membrane proteins in Caco2 intestinal epithelial cells. J Cell Biol 113(2): $275-288$

Gills JJ, Dennis PA (2009) Perifosine: update on a novel Akt inhibitor. Curr Oncol Rep 11(2): $102-110$

Hague A, Paraskeva C (1995) The short-chain fatty acid butyrate induces apoptosis in colorectal tumour cell lines. Eur J Cancer Prev 4(5): 359 - 364

Hao H, Muniz-Medina VM, Mehta H, Thomas NE, Khazak V, Der CJ, Shields JM (2007) Context-dependent roles of mutant B-Raf signaling in melanoma and colorectal carcinoma cell growth. Mol Cancer Ther 6(8): $2220-2229$

Higuchi M, Masuyama N, Fukui Y, Suzuki A, Gotoh Y (2001) Akt mediates Rac/Cdc42-regulated cell motility in growth factor-stimulated cells and in invasive PTEN knockout cells. Curr Biol 11(24): 1958-1962

Hoeflich KP, Luo J, Rubie EA, Tsao MS, Jin O, Woodgett JR (2000) Requirement for glycogen synthase kinase-3beta in cell survival and NF-kappaB activation. Nature 406(6791): 86-90

Ilyas M, Tomlinson IP, Rowan A, Pignatelli M, Bodmer WF (1997) Betacatenin mutations in cell lines established from human colorectal cancers. Proc Natl Acad Sci USA 94(19): 10330-10334

Johnson DI (1999) Cdc42: An essential Rho-type GTPase controlling eukaryotic cell polarity. Microbiol Mol Biol Rev 63(1): 54-105

Jope RS, Johnson GV (2004) The glamour and gloom of glycogen synthase kinase-3. Trends Biochem Sci 29(2): 95-102

Kim M, Datta A, Brakeman P, Yu W, Mostov KE (2007) Polarity proteins PAR6 and aPKC regulate cell death through GSK-3beta in 3D epithelial morphogenesis. J Cell Sci 120(Pt 14): 2309-2317

Koch S, Capaldo CT, Samarin S, Nava P, Neumaier I, Skerra A, Sacks DB, Parkos CA, Nusrat A (2009) Dkk-1 inhibits intestinal epithelial cell migration by attenuating directional polarization of leading edge cells. Mol Biol Cell 20(22): 4816-4825

Kolsch V, Charest PG, Firtel RA (2008) The regulation of cell motility and chemotaxis by phospholipid signalling. J Cell Sci 121(Pt 5): $551-559$

Koseoglu S, Lu Z, Kumar C, Kirschmeier P, Zou J (2007) AKT1, AKT2 and AKT3-dependent cell survival is cell line-specific and knockdown of all three isoforms selectively induces apoptosis in 20 human tumor cell lines. Cancer Biol Therapy 6(5): $755-762$

Langlois MJ, Bergeron S, Bernatchez G, Boudreau F, Saucier C, Perreault N, Carrier JC, Rivard N (2010) The PTEN phosphatase controls intestinal epithelial cell polarity and barrier function: role in colorectal cancer progression. PLoS One 5(12): e15742

Lawson KR, Ignatenko NA, Piazza GA, Cui H, Gerner EW (2000) Influence of K-ras activation on the survival responses of Caco-2 cells to the chemopreventive agents sulindac and difluoromethylornithine. Cancer Epidemiol Biomarkers Prev 9(11): 1155-1162

Lee C, Kim JS, Waldman T (2004) PTEN gene targeting reveals a radiationinduced size checkpoint in human cancer cells. Cancer Res 64(19): 6906-6914

Lee SH, Poulogiannis G, Pyne S, Jia S, Zou L, Signoretti S, Loda M, Cantley LC, Roberts TM (2010) A constitutively activated form of the p110beta isoform of PI3-kinase induces prostatic intraepithelial neoplasia in mice. Proc Natl Acad Sci USA 107(24): 11002-11007

Liliental J, Moon SY, Lesche R, Mamillapalli R, Li D, Zheng Y, Sun H, Wu H (2000) Genetic deletion of the Pten tumor suppressor gene promotes cell motility by activation of Rac1 and Cdc42 GTPases. Curr Biol 10(7): $401-404$ 
Liu SG, Wang BS, Jiang YY, Zhang TT, Shi ZZ, Yang Y, Yang YL, Wang XC, Lin DC, Zhang Y, Yang H, Cai Y, Zhan QM, Wang MR (2011) Atypical protein kinase $\mathrm{C}$ (iota) (PKC(iota)) promotes metastasis of esophageal squamous cell carcinoma by enhancing resistance to anoikis via PKC(iota)-SKP2-AKT pathway. Mol Cancer Res

Lu Y, Lin YZ, LaPushin R, Cuevas B, Fang X, Yu SX, Davies MA, Khan H, Furui T, Mao M, Zinner R, Hung MC, Steck P, Siminovitch K, Mills GB (1999) The PTEN/MMAC1/TEP tumor suppressor gene decreases cell growth and induces apoptosis and anoikis in breast cancer cells. Oncogene 18(50): 7034-7045

Maccario H, Perera NM, Davidson L, Downes CP, Leslie NR (2007) PTEN is destabilized by phosphorylation on Thr366. Biochem J 405(3): 439-444

Maehama T, Dixon JE (1999) PTEN: a tumour suppressor that functions as a phospholipid phosphatase. Trends Cell Biol 9(4): 125-128

Mai W, Kawakami K, Shakoori A, Kyo S, Miyashita K, Yokoi K, Jin M, Shimasaki T, Motoo Y, Minamoto T (2009) Deregulated GSK3(beta) sustains gastrointestinal cancer cells survival by modulating human telomerase reverse transcriptase and telomerase. Clin Cancer Res 15(22): $6810-6819$

Martin-Belmonte F, Gassama A, Datta A, Yu W, Rescher U, Gerke V, Mostov K (2007) PTEN-mediated apical segregation of phosphoinositides controls epithelial morphogenesis through Cdc42. Cell 128(2): 383-397

Melendez J, Grogg M, Zheng Y (2011) Signalling role of Cdc42 in regulating mammalian physiology. J Biol Chem 286(4): 2375-2381

Na S, Li B, Grewal IS, Enslen H, Davis RJ, Hanke JH, Flavell RA (1999) Expression of activated CDC42 induces $\mathrm{T}$ cell apoptosis in thymus and peripheral lymph organs via different pathways. Oncogene 18(56): $7966-7974$

Pap M, Cooper GM (1998) Role of glycogen synthase kinase-3 in the phosphatidylinositol 3-Kinase/Akt cell survival pathway. J Biol Chem 273(32): $19929-19932$

Riccardi C, Nicoletti I (2006) Analysis of apoptosis by propidium iodide staining and flow cytometry. Nat Protoc 1(3): 1458-1461

Schlessinger K, McManus EJ, Hall A (2007) Cdc42 and noncanonical Wnt signal transduction pathways cooperate to promote cell polarity. J Cell Biol 178(3): $355-361$

Sun H, Lesche R, Li DM, Liliental J, Zhang H, Gao J, Gavrilova N, Mueller B, Liu X, Wu H (1999) PTEN modulates cell cycle progression and cell survival by regulating phosphatidylinositol 3,4,5,-trisphosphate and Akt/protein kinase B signalling pathway. Proc Natl Acad Sci USA 96(11): 6199-6204

Tang M, Iijima M, Kamimura Y, Chen L, Long Y, Devreotes P (2011) Disruption of PKB signalling restores polarity to cells lacking tumor suppressor PTEN. Mol Biol Cell 22(4): 437-447

UKCCCR guidelines for the use of cell lines in cancer research (2000) $\mathrm{Br} \mathrm{J}$ Cancer 82(9): 1495-509

Vitolo MI, Weiss MB, Szmacinski M, Tahir K, Waldman T, Park BH, Martin SS, Weber DJ, Bachman KE (2009) Deletion of PTEN promotes tumorigenic signalling, resistance to anoikis, and altered response to chemotherapeutic agents in human mammary epithelial cells. Cancer Res 69(21): $8275-8283$

Walker GE, Wilson EM, Powell D, Oh Y (2001) Butyrate, a histone deacetylase inhibitor, activates the human IGF binding protein-3 promoter in breast cancer cells: molecular mechanism involves an Sp1/ Sp3 multiprotein complex. Endocrinology 142(9): 3817-3827

Wang L, Yang L, Luo Y, Zheng Y (2003) A novel strategy for specifically down-regulating individual Rho GTPase activity in tumor cells. J Biol Chem 278(45): 44617-44625

Wang Q, Wang X, Hernandez A, Kim S, Evers BM (2001) Inhibition of the phosphatidylinositol 3-kinase pathway contributes to HT29 and Caco2 intestinal cell differentiation. Gastroenterology 120(6): 1381-1392

Wang Q, Zhou Y, Wang X, Chung DH, Evers BM (2007) Regulation of PTEN expression in intestinal epithelial cells by c-Jun NH2-terminal kinase activation and nuclear factor-kappaB inhibition. Cancer Res 67(16): $7773-7781$

Warner SJ, Yashiro H, Longmore GD (2010) The Cdc42/Par6/aPKC Polarity Complex Regulates Apoptosis-Induced Compensatory Proliferation in Epithelia. Current Biol 20(8): 677-686

Weng L, Brown J, Eng C (2001) PTEN induces apoptosis and cell cycle arrest through phosphoinositol-3-kinase/Akt-dependent and -independent pathways. Hum Mol Genet 10(3): 237-242

Yap TA, Garrett MD, Walton MI, Raynaud F, de Bono JS, Workman P (2008) Targeting the PI3K-AKT-mTOR pathway: progress, pitfalls, and promises. Curr Opin Pharmacol 8(4): 393-412

Zhou FQ, Snider WD (2005) Cell biology. GSK-3beta and microtubule assembly in axons. Science 308(5719): 211-214

This work is published under the standard license to publish agreement. After 12 months the work will become freely available and the license terms will switch to a Creative Commons Attribution-NonCommercial-Share Alike 3.0 Unported License. 